\title{
Association between Diagonal Earlobe Crease and Cardio-Ankle Vascular Index in Asymptomatic Hypertensive Patients
}

\author{
Levent Korkmaz Mustafa Tarık Ağaç Hakan Erkan Zeydin Acar Ismail Gurbak \\ Huseyin Bektas Devrim Kurt Şükrü Çelik \\ Department of Cardiology, Ahi Evren Cardiovascular and Thoracic Surgery Training and Research Hospital, \\ Trabzon, Turkey
}

\section{Key Words}

Cardio-ankle vascular index · Earlobe crease $\cdot$ Hypertension

\begin{abstract}
Objective: The aim of this study was to investigate the association between earlobe crease (ELC) and cardio-ankle vascular index (CAVI) in asymptomatic hypertensive subjects. Materials and Methods: A total of 75 subjects with ELC and 75 age- and gender-matched patients without ELC were prospectively selected from subjects admitted to the Outpatient Cardiology Clinic. ELC was assigned to a person with a crease stretching obliquely from the outer ear canal towards the border of the earlobe of at least one ear. CAVI was assessed by a VaSera VS-1000 instrument. Results: There were statistically significant higher CAVI values in ELC subjects $(9.8 \pm 2.1$ vs. 8.6 $\pm 1.6, p<0.001)$. There was a significant and positive association between CAVI and age $(r=0.42, p<0.001)$, ELC $(r=0.31$, $p<0.001)$, BMI $(0.20, p<0.001)$ and male gender $(r=0.21$, $\mathrm{p}=0.04)$. Linear regression analysis demonstrated ELC $(95 \%$ confidence interval, $\mathrm{Cl}, 0.61-1.74, \mathrm{p}=0.009)$, age $(95 \% \mathrm{Cl}$ $0.03-0.09, \mathrm{p}<0.001)$ and male gender $(95 \% \mathrm{Cl} 0.48-1.55, \mathrm{p}=$ 0.03 ) as independent determinants of CAVI. Also, there was a higher prevalence of ELC in subjects with subclinical atherosclerosis $(C A V I \geq 9)$ than in normal subjects $(C A V I<9)$. Conclu-
\end{abstract}

sion: Patients with ELC had higher CAVI than normal subjects. This observation of ELC is simple, adds no cost and can be easily made by most physicians, and it may provide important predictive information of arterial stiffness and subclinical atherosclerosis in asymptomatic hypertensive subjects.

(c) 2013 S. Karger AG, Basel

\section{Introduction}

Arterial stiffness is increasingly recognized as a surrogate end point for cardiovascular disease [1] and is an important risk factor for cardiovascular morbidity and mortality $[2,3]$. Also, increased arterial stiffness is a possible simultaneous risk for atherosclerotic cardiovascular disease and diastolic heart failure in patients with hypertension [4]. Hence, arterial elastic properties are increasingly used for risk stratification purposes in several populations and, recently, the European Society of Hypertension/European Society of Cardiology guidelines for the management of arterial hypertension suggested the evaluation of arterial stiffness as a tool for the assessment of subclinical target organ damage [5].

Cardio-ankle vascular index (CAVI) is considered to reflect arteriosclerosis of the aorta and is a novel param-

\begin{tabular}{ll}
\hline KARGER & $\begin{array}{l}\text { ( ) 2013 S. Karger AG, Basel } \\
1011-7571 / 13 / 0226-0530 \$ 38.00 / 0 \quad \text { Karger }\end{array}$ \\
$\begin{array}{l}\text { E-Mail karger@karger.com } \\
\text { www.karger.com/mpp }\end{array}$ & $\begin{array}{l}\text { This is an Open Access article licensed under the terms of the } \\
\text { Creative Commons Attribution-NonCommercial 3.0 Un- } \\
\text { ported license (CC BY-NC) (www.karger.com/OA-license), } \\
\text { applicable to the online version of the article only. Distribu- } \\
\text { tion permitted for non-commercial purposes only. }\end{array}$
\end{tabular}

Levent Korkmaz, MD

Department of Cardiology

Ahi Evren Cardiovascular and Thoracic Surgery Training and Research Hospital

TR-61010 Trabzon (Turkey)

E-Mail l.korkmaz@yahoo.com 
eter of arterial stiffness and surrogate marker of subclinical atherosclerosis [6]. Diagonal earlobe crease (ELC) is a wrinkle-like line extending diagonally from the tragus across the lobule to the rear edge of the auricle of the ear [7]. The presence of ELC is associated with increased allcause and cardiac morbidity and mortality in patients with and without coronary artery disease. However, there is no study investigating any possible association between CAVI and ELC in asymptomatic hypertensive subjects. Therefore, the main purpose of this study was to investigate any such association.

\section{Subjects and Methods}

\section{Subjects}

A total of 75 subjects with ELC and 75 age- and gender-matched patients without ELC were prospectively selected from the Cardiology Outpatient Clinic, Ahi Evren Thoracic and Cardiovascular Surgery Training and Research Hospital, Trabzon, Turkey. Exclusion criteria were patients with moderate-to-severe valvular disease including prosthetic valves, bicuspid aortic valves, congenital heart disease, bacterial endocarditis, atrial fibrillation or hypertrophic obstructive cardiomyopathy, as well as those who had suffered from symptomatic vascular disease such as stroke, transient ischemia, coronary heart disease, congestive heart failure and intermittent claudication. Coronary heart disease was defined as self-reported myocardial infarction, angina or use of nitroglycerin, as well as self-reported history of coronary angioplasty or coronary artery bypass surgery. Cerebrovascular disease was defined as selfreported stroke, transient ischemic attack or carotid endarterectomy. The presence of a diagonal ELC was assigned to a person with a crease stretching obliquely from the outer ear canal towards the border of the earlobe of at least one ear. The Ethics Committee of the institution approved the study and informed consent was obtained from all subjects.

\section{Assessment of Cardiovascular Risk Factors}

In addition to questions about the symptoms of ischemic heart disease, peripheral vascular disease and stroke, data on cardiovascular risk factors, diabetes mellitus, arterial hypertension and smoking habits were obtained. Patients were considered to be hypertensive if they had systolic blood pressure $>140 \mathrm{~mm} \mathrm{Hg}$ and/or diastolic pressure $>90 \mathrm{~mm} \mathrm{Hg}$ or were using antihypertensive drugs. Subjects with fasting glucose $\geq 126 \mathrm{mg} / \mathrm{dl}$ and/or use of pharmacological treatment were considered as having diabetes. Smoking was defined as 'current smokers' or 'nonsmokers'. Hypercholesterolemia was defined as total cholesterol $>200 \mathrm{mg} / \mathrm{dl}$ or taking medications. Body mass index (BMI) was calculated as weight (kilograms)/height ${ }^{2}$ (meters).

\section{Arterial Stiffness Measurements}

Arterial stiffness was assessed by CAVI. It was measured using a VaSera VS-1000 CAVI instrument (Fukuda Denshi Co. Ltd., Tokyo, Japan), using a previously described method [7], in the morning after $12 \mathrm{~h}$ of fasting. Briefly, cuffs were applied to the bilateral upper arms and ankles, with the subject lying supine and the head held in the midline position. After resting for $10 \mathrm{~min}$ the following measurements were performed: electrography, phonocardiography, and pressure and waveforms of brachial and ankle arteries. Thereafter, CAVI was calculated automatically and gave left and right CAVI values; if the higher value was chosen there were differences in left and right CAVIs. Based on the manufacturer's recommendations, CAVI $<8$ was considered normal, 8 to $<9$ borderline and $\geq 9$ abnormal [8].

\section{Statistical Analysis}

Continuous variables were expressed as mean \pm standard deviation and categorical variables were expressed as percentages. An analysis of normality of the continuous variables was performed with the Kolmogorov-Smirnov test. A comparison of the categorical variables between the patients with and without ECL was performed using a $\chi^{2}$ test. Continuous variables were compared using the unpaired t test and Mann-Whitney U test. Spearman's and Pearson's correlation analyses were performed to assess the association between CAVI and ELC. Linear regression analysis was performed to find the independent determinant of CAVI. A p value $<0.05$ was considered statistically significant. Statistical analysis was done using SPSS 14.0 statistical software.

\section{Results}

Clinical and laboratory characteristics of subjects with and without ELC are given in table 1. Subjects with ELC had higher rate of diabetes, smoking and BMI. There was a statistically significant difference in CAVI values between subjects with and without ELC $(9.8 \pm 2.1$ vs. $8.6 \pm 1.6, \mathrm{p}<0.001$; fig. 1$)$. There was a significant and positive association between CAVI and age $(\mathrm{r}=$ $0.42, \mathrm{p}<0.001)$, ELC $(\mathrm{r}=0.31, \mathrm{p}<0.001)$, BMI $(0.20$, $\mathrm{p}<0.001)$ and male gender $(\mathrm{r}=0.21, \mathrm{p}=0.04)$ and $\mathrm{a}$ negative correlation with cholesterol-lowering therapies $(\mathrm{r}=-0.17, \mathrm{p}=0.03)$. Linear regression analysis showed ELC (95\% confidence interval, CI, 0.61-1.74, $\mathrm{p}=0.009$ ), age $(95 \%$ CI $0.03-0.09, \mathrm{p}<0.001)$ and male gender $(95 \%$ CI $0.48-1.55, \mathrm{p}=0.03$ ) as independent determinants of CAVI (table 2).

The numbers of subjects with normal, borderline and abnormal CAVI values were 40, 27 and 83, respectively, while the numbers of patients with ELC in these CAVI values were as follows: normal $=11(28 \%)$, borderline $=$ $15(20 \%)$ and abnormal $=49$ (65\%; $\mathrm{p}=0.004$; fig. 2$)$.

\section{Discussion}

The findings revealed increased CAVI values in asymptomatic hypertensive subjects with ELC. Also, there was an increased prevalence of ELC in subjects with abnormal and borderline CAVI values. 
Table 1. Clinical and laboratory characteristics of subjects with and without ELC

\begin{tabular}{|c|c|c|c|}
\hline & $\begin{array}{l}\operatorname{ELC}(-) \\
(\mathrm{n}=75)\end{array}$ & $\begin{array}{l}\operatorname{ELC}(+) \\
(n=75)\end{array}$ & $\begin{array}{l}\mathrm{p} \\
\text { value }\end{array}$ \\
\hline Age, years & $67 \pm 12$ & $65 \pm 12$ & 0.32 \\
\hline Male gender, $\mathrm{n}$ & $30(40)$ & $38(50)$ & 0.15 \\
\hline Diabetes, $\mathrm{n}$ & $11(15)$ & $22(29)$ & 0.02 \\
\hline Smoking, $\mathrm{n}$ & $5(7)$ & $14(19)$ & 0.002 \\
\hline Dyslipidemia & $22(29)$ & $15(20)$ & 0.17 \\
\hline $\mathrm{BMI}$ & $26 \pm 5$ & $28 \pm 6$ & 0.004 \\
\hline $\mathrm{LDL}, \mathrm{mg} / \mathrm{dl}$ & $139 \pm 37$ & $137 \pm 38$ & 0.18 \\
\hline $\mathrm{HDL}, \mathrm{mg} / \mathrm{dl}$ & $47 \pm 12$ & $43 \pm 13$ & 0.25 \\
\hline Triglyceride, mg/dl & $148 \pm 68$ & $149 \pm 69$ & 0.79 \\
\hline Cholesterol, mg/dl & $208 \pm 44$ & $205 \pm 51$ & 0.33 \\
\hline Systolic blood pressure, $\mathrm{mm} \mathrm{Hg}$ & $144 \pm 23$ & $142 \pm 21$ & 0.61 \\
\hline Diastolic blood pressure, $\mathrm{mm} \mathrm{Hg}$ & $89 \pm 9$ & $91 \pm 11$ & 0.12 \\
\hline Heart rate, beats/min & $76 \pm 18$ & $72 \pm 12$ & 0.34 \\
\hline CAVI & $8.6 \pm 1.6$ & $9.8 \pm 2.1$ & $<0.001$ \\
\hline \multicolumn{4}{|l|}{ Cardiovascular medication } \\
\hline ACE inhibitors or ARB, $n$ & $55(73)$ & $47(63)$ & 0.16 \\
\hline Calcium channel blockers, $\mathrm{n}$ & $32(43)$ & $29(39)$ & 0.42 \\
\hline$\beta$-Blockers, $\mathrm{n}$ & $18(24)$ & $15(20)$ & 0.12 \\
\hline Cholesterol-lowering drugs, $\mathrm{n}$ & $16(21)$ & $13(17)$ & 0.51 \\
\hline Aspirin, $n$ & $32(43)$ & $23(31)$ & 0.21 \\
\hline
\end{tabular}

Values in parentheses are percentages. $\mathrm{ACE}=$ Angiotensin-converting enzyme; $\mathrm{ARB}=$ angiotensin receptor blocker; HDL = high density cholesterol; LDL = low density cholesterol.

Table 2. Correlation and regression analyses of CAVI and other variables

\begin{tabular}{|c|c|c|c|c|}
\hline & \multicolumn{2}{|c|}{ Correlation analysis } & \multicolumn{2}{|c|}{ Regression analysis } \\
\hline & $\mathrm{r}$ & $\mathrm{p}$ & $95 \%$ CI & $\mathrm{p}$ \\
\hline Age & 0.42 & $<0.001$ & $0.03-0.09$ & $<0.001$ \\
\hline Male gender & 0.21 & 0.04 & $0.48-1.55$ & 0.03 \\
\hline Hypertension & 0.06 & 0.41 & - & - \\
\hline Diabetes & 0.06 & 0.44 & - & - \\
\hline Smoking & 0.05 & 0.79 & - & - \\
\hline Dyslipidemia & 0.16 & 0.06 & $-1.4-0.21$ & 0.16 \\
\hline $\mathrm{BMI}$ & 0.20 & $<0.001$ & $-0.02-0.08$ & 0.22 \\
\hline ELC & 0.31 & $<0.001$ & $0.61-1.74$ & 0.009 \\
\hline \multicolumn{5}{|l|}{ Cardiovascular medication } \\
\hline ACE inhibitors or ARB & -0.02 & 0.76 & - & - \\
\hline Calcium channel blockers & 0.15 & 0.40 & - & - \\
\hline$\beta$-Blockers & -0.21 & 0.07 & $-0.56-1.34$ & 0.41 \\
\hline Cholesterol-lowering drugs & -0.17 & 0.03 & $-2.52-0.78$ & 0.29 \\
\hline Aspirin & 0.05 & 0.26 & - & - \\
\hline
\end{tabular}

$\mathrm{ACE}=$ Angiotensin-converting enzyme; $\mathrm{ARB}=$ angiotensin receptor blocker. 


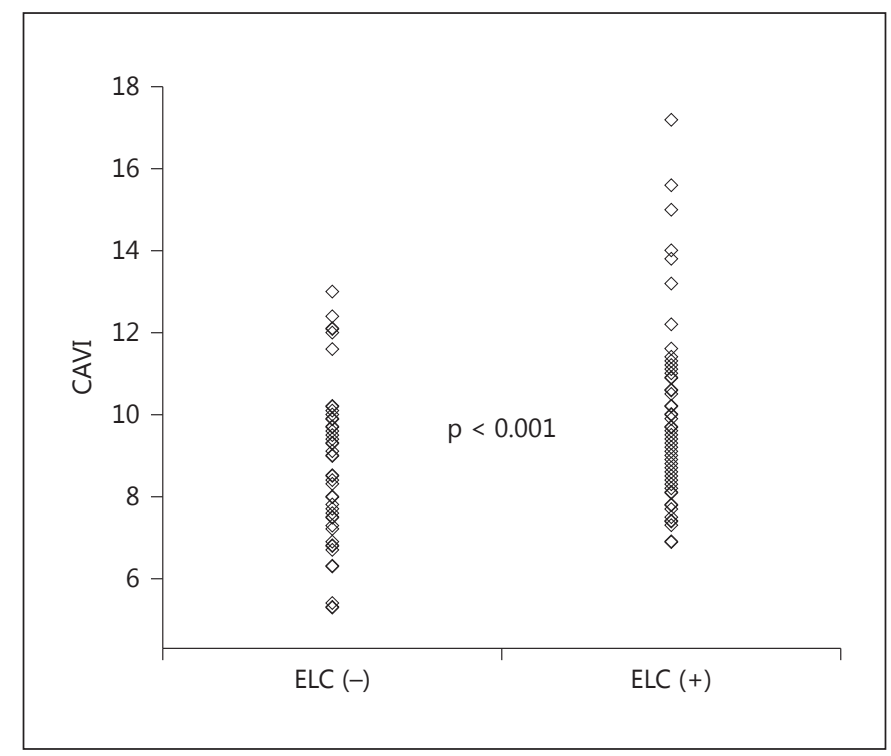

Fig. 1. CAVI values in patients with and without ELC.

Several alterations in vascular structure have been described in patients with systemic hypertension [9-11], and most cardiovascular events are the consequence of a progressive vascular disease. Arterial disease does not begin with the first clinical event but develops long before without symptoms. Identifying asymptomatic individuals with subclinical arterial disease may be considered as the best current screening test for predicting subsequent coronary heart disease events and offering them aggressive risk reduction therapy. In recent years, therefore, great emphasis has been placed in identifying patients with subclinical atherosclerosis $[10,11]$. However, traditional risk factors are poor screening tests for atherosclerotic vascular disease [10].

Stiffness of large arteries has been related to cardiovascular mortality and CAVI is considered to reflect arteriosclerosis of the aorta and is a novel parameter of arterial stiffness and a surrogate marker of subclinical atherosclerosis. Okura et al. [12] demonstrated a significant correlation between CAVI and carotid intima-media thickness, another well-known surrogate marker of subclinical atherosclerosis, and suggested that CAVI was a useful clinical marker for evaluating subclinical atherosclerosis in patients with essential hypertension.

Several studies demonstrated a significant association between ELC and atherosclerotic cardiovascular risk factors [13-15]. Other investigators also found a significant

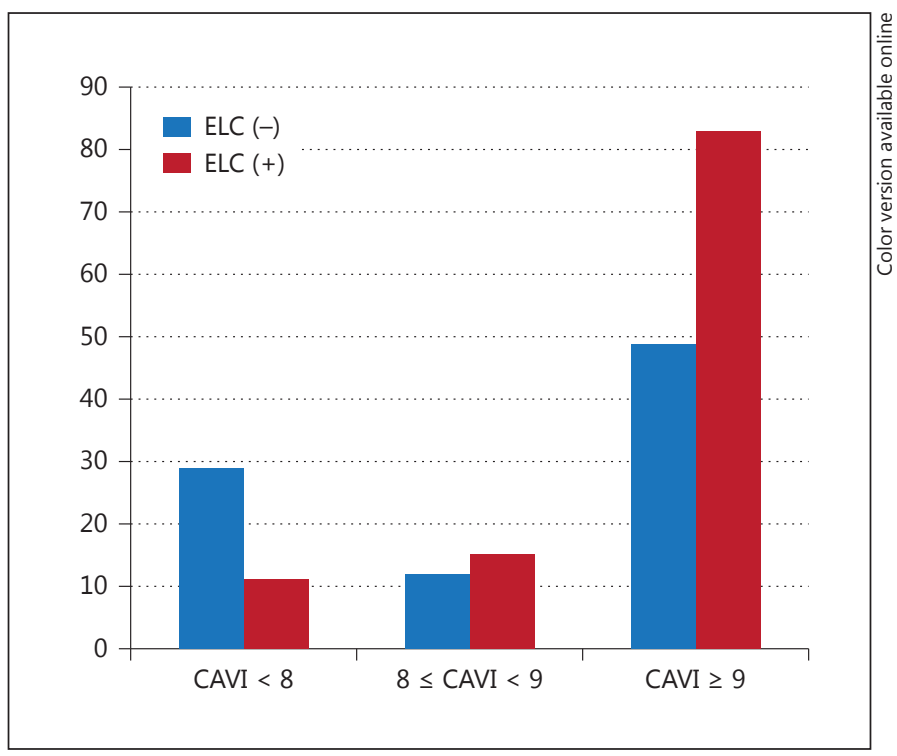

Fig. 2. Distribution of subjects according to the CAVI categories.

association between ELC and carotid intima-media thickness $[16,17]$. Previous researchers suggested that possible mechanisms linking ELC and coronary heart disease could be the consequences of systemic loss of elastin and elastic fiber. Also, changes in the ratio of collagen to elastin have been known to structurally affect the elastic behavior of the arterial wall. This pathological mechanism might be a possible explanation for increased arterial stiffness in subjects with ELC.

The limitations of this study include small sample size and only hypertensive patients in our study. Therefore, this finding may not be extrapolated to the general population.

\section{Conclusion}

The presence of ELC was significantly and independently associated with CAVI in asymptomatic hypertensive subjects. Hence, we recommend that physicians should pay attention to the evaluation of ELC, which may be helpful in detecting asymptomatic hypertensive patients with subclinical atherosclerosis. 


\section{References}

$>1$ Laurent S, Cockcroft J, Van Bortel L, et al: European Network for Non-Invasive Investigation of Large Arteries. Expert consensus document on arterial stiffness: methodological issues and clinical applications. Eur Heart J 2006;27:2588-2605.

2 Laurent S, Boutouyrie P, Asmar R, et al: Aortic stiffness is an independent predictor of allcause and cardiovascular mortality in hypertensive patients. Hypertension 2001;37:12361241.

$\checkmark 3$ Blacher J, Asmar R, Djane S, et al: Aortic pulse wave velocity as a marker of cardiovascular risk in hypertensive patients. Hypertension 1999;33:1111-1117.

4 Yambe M, Tomiyama H, Hirayama Y, et al: Arterial stiffening as a possible risk factor for both atherosclerosis and diastolic heart failure. Hypertens Res 2004;27:625-631.

$\checkmark 5$ Mancia G, De Backer G, Dominiczak A, et al: 2007 guidelines for the management of arterial hypertension: the Task Force for the Management of Arterial Hypertension of the European Society of Hypertension (ESH) and of the European Society of Cardiology (ESC). J Hypertens 2007;25:1105-1187.
6 Takaki A, Ogawa H, Wakeyama T, et al: Cardio-ankle vascular index is a new noninvasive parameter of arterial stiffness. Circ J 2007;71: 1710-1714.

$>7$ Frank S: Aural sign of coronary-artery disease. N Engl J Med 1973;289:327-328.

8 VaSera VS-1000 operation manual, Fukuda Denshi Co. Ltd., Tokyo, Japan. http://www. fukuda.co.jp/english/products/special_features/vasera/cavi.html.

-9 Simon A, Chironi G, Levenson J: Performance of subclinical arterial disease detection as a screening test for coronary heart disease. Hypertension 2006;48:392-396.

10 Greenland P, Smith SC Jr, Grundy SM: Improving coronary heart disease risk assessment in asymptomatic people: role of traditional risk factors and noninvasive cardiovascular tests. Circulation 2001;104:1863-1867.

11 Pitt B, Rubenfire M: Risk stratification for the detection of preclinical coronary artery disease. Circulation 1999;99:2610-2612.

12 Okura T, Watanabe S, Kurata M, et al: Relationship between cardio-ankle vascular index (CAVI) and carotid atherosclerosis in patients with essential hypertension. Hypertens Res 2007;30:335-340.
3 Tranchesi B Jr, Barbosa V, de Albuquerque $\mathrm{CP}$, et al: Diagonal ear lobe crease as a marker of the presence and extent of coronary atherosclerosis. Am J Cardiol 1992;70:1417-1420.

14 Kirkham N, Murrells T, Melcher DH, et al: Diagonal earlobe creases and fatal cardiovascular disease: a necropsy study. Br Heart J 1989;61:361-364.

15 Elliott WJ, Karrison T: Increased all-cause and cardiac morbidity and mortality associated with the diagonal earlobe crease: a prospective cohort study. Am J Med 1991;91: 247-254.

16 Celik S, Erdoğan T, Gedikli O, et al: Diagonal ear-lobe crease is associated with carotid intima-media thickness in subjects free of clinical cardiovascular disease. Atherosclerosis 2007; 192:428-431.

17 Shrestha I, Ohtsuki T, Takahashi T, et al: Diagonal ear-lobe crease is correlated with atherosclerotic changes in carotid arteries. Circ J 2009;73:1945-1949. 